\title{
MOHAMED SAAD, SAAD (COORD.). ESTUDIOS DE TRADUCTOLOGÍA ÁRABE. TRADUCCIÓN DEL TEXTO NARRATIVO. GRANADA: COMARES, 2021, 128 PP., ISBN: 978-84-1369-111-4
}

Estudios de traductología árabe. Traducción del texto narrativo forma parte de una serie dedicada a varios aspectos de la traducción de textos literarios de diferente índole del español al árabe, y viceversa. Contiene cinco capítulos ofrecidos por profesores egipcios y españoles, especialistas en traductología, que ejercen también una labor traductora. Así, el libro sintetiza la experiencia profesional y académica de sus autores. En el primer estudio, «Anotaciones en torno a la traducción al español de los aspectos culturales en Yawmiyyāt nāỉb fi-l-aryāf de Tawfīq al-Hakīm», Saad Mohamed Saad, de la Universidad Pablo de Olavide, examina la traducción de los culturemas en esta obra del novelista y dramaturgo egipcio Tawfíq al-Hakīm, para comprobar hasta qué punto el traductor logra mantener el to no local y cultural del texto al trasvasarlo del árabe al español. Para conseguir su objetivo, Mohamed analiza la traducción española de esta obra, tanto desde una perspectiva cualitativa como cuantitativa. Según el autor, la importancia del estudio de los culturemas en la obra aludida reside en que estos elementos pueden comportar información implícita a la que tendrán acceso todos los individuos que pertencen a la cultura del texto origen, condición que tal vez no compartan los lectores del texto meta. En el análisis cualitativo, Mohamed intenta averiguar el grado de transmisión del contenido, tanto implícito como explícito, que los culturemas pueden comportar en la versión española de Yawmiyyāt nāỉb fi-l-aryāf en comparación con el texto original de Tawfiq al-Hakīm. Cabe señalar aquí que el trasvase de los culturemas adquiere su importancia en este caso de las circunstancias de publicación de la obra original y s u contenido, cuyo tema se desarrolla en la primera mitad del siglo XX, una época diferente del momento actual, en la que Egipto era un país poco desarrollado y con multitud de realidades ya desaparecidas. La brecha es aún mayor entre este Egipto y el lecto r español. Debido a ello, tal como afirma el mismo investigador, «el interés de García Gómez se centra, en líneas generales, en aportar un valor contextual adecuado a lo que quiere conceder el autor de la obra original al culturema empleado, más que en transmitir una imagen fiel, pero rígida, de su denotatum». El estudio concluye que García Gómez consigue transmitir tanto el contenido inferencial como el referencial con gran maestría y habilidad. Respecto al análisis cuantitativo, el estudioso detecta el uso de ocho técnicas traslativas, que ordena en función de su frecuencia de uso. Según Mohamed, el hecho de optar por una técnica u otra reflejará la tendencia del propio traductor hacia una u otra de las dos grandes estrategias de traducción: la domesticación o la extranjerización. El análisis cuantitativo desvela que en la traducción se opta por una estrategia más domesticante que extranjerizante, así como por un estilo más conservador que transgresor, a fin de conservar to dos los rasgos posibles de la leng ua origen.

En su estudio, titulado «Fraseología árabe, histo ria y traducción: las locuciones en dos versiones españolas de Amor bajo la lluvia de Naŷīb Maḥfūẓ», Ahmed Shafik, de la Universidad de Oviedo, analiza la traducción de las unidades fraseológicas en dos versiones españolas de al-Hubb taht al-mațar (Amor bajo la lluvia), del Premio

Hikma 20 (2) (2021), 429 - 432 
Nobel egipcio Naŷīb Maḥūž, centrando su atención en la problemática del trasvase de las locuciones verbales, por un lado, y los procedimientos empleados por las traductoras, por el otro. La primera traducción es la de Mercedes del Amo, publicada en 1988. Isabel Hervás Jávega es la traductora de la segunda versión, publicada en 1999. A modo de introducción, el autor del trabajo hace un recorrido histórico por las investigaciones relacionadas con la fraseología dentro de la lingüística árabe, resaltando en los antiguos la falta de criterios semánticos para la clasificación de este tipo de unidades lingüísticas, mientras las investigaciones modernas carecen de interés por consolidar una metodología precisa para su recopilación y análisis, lo cual hace que la tarea de su traducción sea sumamente difícil. El investigador, adoptando un método contrastivo, intenta estudiar las posibles correspondencias entre las dos lenguas, así como las relaciones de (in)equivalencia entre las locuciones utilizadas en las versiones de la obra sometidas al análisis. Y a pesar de que Shafik detecta algunos paralelismos fraseológicos entre el español y el árabe en diferentes ocasiones, afirma que las traductoras prefieren recurrir al uso de técnicas como la paráfrasis, la omisión o el calco. Shafik critica la labor de ambas traductoras, especialmente la de Mercedes del Amo, puesto que cree que comete fallos a la hora de identificar los frasemas. $E$ autor del artículo achaca este defecto a dos factores esenciales: las carencias relacionadas con el tratamiento de las frases hechas en los diccionarios bilingües y la rapidez en traducir a un autor que acababa de ganar el Premio Nobel. Entre las conclusiones destacadas de este estudio, se puede señalar la relevancia de las frases hechas o el discurso repetido a la hora de orientar las estrategias traslatorias. El traductor de la obra mahfuziana debe tener en cuenta uno de los rasgos esenciales del estilo del autor, que descansa principalmente en el uso y la manipulación de las unidades fraseológicas, empleando recursos como la adición, reducción, sustitución, fusión y adecuación del habla egipcia al árabe clásico.

El Prof. Dr. Mohamed El Madkouri Maataoui, de la Universidad Autónoma de Madrid, toca un aspecto de gran importancia y sumo interés: la traducción de la literatura considerando las técnicas literarias empleadas, y que están relacionadas con el registro lingüístico. Así Maataoui centra su estudio en el análisis del uso de la diglosia en la narrativa árabe y la problemática de su traducción al español. El autor del artículo se basa tanto en su experiencia profesional co mo en el examen que hace de un corpus constituido por las versiones original y traducida de diversas obras de escritores árabes modernos, tales como los autores egipcios Khalid al-Khamissi y Naguib Mahfuz o el novelista marroquí Mohammed Berrada. En su capítulo, el Prof. Madkouri parte de las técnicas propias de la lingüística del texto, así co mo del análisis del discurso y la etnografía de la comunicación, parallegar a la conclusión de que el uso de la diglosia sitúa la traducción en el límite de sus posibilidades. Maataoui hace hincapié en que el empleo de la diglosia no es un descuido por parte de los autores; tampoco se considera como señal de una incapacidad expresiva en árabe Fuṣhá, sino más bien un instrumento que cumple varias funciones literarias y traductológicas, entre las cuales se pueden señalar: la creación de cierta verosimilitud en los textos narrativos, la comunicación de algunos contenidos semánticos o la denuncia social.

Cabe recalcar las valiosas conclusiones que aporta este estudio en relación con el uso de la diglosia en la novela como fenómeno cultural. Estas conclusiones subrayan la falta de «señal alguna tanto explícita como implícita que haga al lector

Hikma 20 (2) (2021), 429 - 432 
español diferenciar los dos discursos lingüísticos. Y que las obras estudiadas han neutralizado la oposición Fușhá/variante diatópica, sin excepción». Según Maataoui los traductores de las obras examinadas podrían haber transmitido el cambio del registro lingüístico efectuado en el original mediante el empleo de alguna variante del registro propio del español, mezclando por ejemplo, entre el estilo formal y el informal, echando mano de una gramática oral, lo que hubiese disminuido el grado de pérdidas significativas y semióticas de un interminable conglomerado de alusiones y referencias culturales entretejidas con la trama de estas obras literarias.

En el cuarto capítulo, los profesores Rosa Isabel Martínez Lillo, de la Universidad de Málaga, y Abdelkhalak Najmi, de la Universidad Autónoma de Madrid, en su estudio titulado: «Narrativa americana de origen árabe: Análisis y propuestas de traducción (El viajero de la alfombra mágica) de Walter Garib y (Las hojas muertas) de Bárbara Jacobs » se centran en dos aspectos relacionados con la traducción de la narrativa americana de origen árabe: la realidad actual de los escritores del denominado post-Mahŷar, y las normas que se deben seguir a la hora de trasladar sus obras al árabe. Los autores del estudio subrayan la importancia de una condición inherente a todo traductor, especialmente el de una obra literaria, y que reside en la obligación de armarse de un conocimiento profundo de la coyuntura histórica que rodea tanto a los autores como al proceso de creación de sus obras. La labor del traductor de los escritores americanos de origen árabe requiere un amplio conocimiento de «la realidad de la literatura americana de origen árabe, y el porqué de sus registros idiomáticos, los usos del español de lberoamérica y, en concreto, de los primeros emigrantes de origen árabe».

Entre las conclusiones importantes de este artículo se puede recalcar el papel del traductor de la narrativa de los escritores de origen árabe, ya que este tendrá que disponer de un bagaje cultural amplio y profundo en lo que concierne a la geografía y la historia, tanto del mundo árabe como del mundo hispano, y preferiblemente este traductor deberá estar dotado de un tinte de creatividad que le permita emplear recursos y estilos literarios a la hora de llevar a cabo la traducción.

Es muy interesante la propuesta de las pautas establecidas por los autores del artículo para el traductor de las obras de Walter Garib y Bárbara Jacobs, por el hecho de que ambos novelistas transgreden la normativa lingüística llevando la lengua a su límite y creando así un verdadero desafío para el traductor de su obra.

En el quinto capítulo, titulado «Normas de traducción en «Al-qurșān $A b u \bar{~}$ 'Arŷān», la versión árabe de la primera novela de la saga de El pirata Garrapata», la profesora Beatriz Soto Aranda, de la Universidad Rey Juan Carlos, examina las normas de traducción empleadas en esta versión, estudiando al mismo tiempo tanto las normas extrínsecas, esto es, las referidas al proceso de publicación de la obra y su recepción en el mundo árabe, como las intrínsecas, relacionadas con la adaptación de las técnicas empleadas en su trasvase teniendo en cuenta las particularidades de un texto que pertenece a la literatura infantil y juvenil. Asimismo, es de suma importancia subrayar la parte que dedica al análisis de la traducción de ciertos culturemas que podrían causar algún tipo de choque o rechazo en el lector de la cultura meta.

Hikma 20 (2) (2021), 429 - 432 
Soto Aranda recalca la importancia de que la traducción analizada debería cumplir las características prototípicas de una traducción de la literatura infantil y juvenil, que es una traducción leída por partes intermediarias como la familia y los centros de docencia que ejercen de filtros para su difusión y lectura. Es importante que se ajuste al sistema educativo de la cultura de destino, por lo cual la do mesticación se convierte en la estrategia más aplicada, tal como señala la autora del capítulo. Según Soto Aranda, traducir un texto destinado al público infantily juvenil es una tarea comunicativa en la que se valora la transmisión de un producto lingüístico cuya función es provocar el mismo efecto en el lector meta, conservando el valor literario de la obra, y sin olvidar que es un género originalmente dedicado a niños y jóvenes.

Entre las conclusiones valiosas de este artículo, cabe señalar el énfasis que pone la autora en la habilidad del traductor, que ha optado por la técnica de la neutralización, buscando términos genéricos no marcados a la hora de traducir términos culturalmente marcados como la alimentación y la bebida. Otra habilidad de índole literaria de la que ha gozado el traductor de El pirata Garrapata es la capacidad creativa que le ha permitido respetar y plasmar los recursos estilísticos característicos del texto origen: rimas, juegos de palabras y repeticiones, entre otros, esforzándose en ofrecer un marco intertextual con la cultura meta que favorezca la lectura de la traducción como si fuera un texto original.

Cabe resaltar que el hilo conductor que enhebra los capítulos del Estudios de traductología árabe es el intento de lograr un estado de perfeccionamiento de diferentes áreas literarias de la traducción del español al árabe, y viceversa, así como recalcar la trascendencia de las estrategias y técnicas empleadas por los traductores para conseguir un buen trasvase de los textos.

[HAYAM ABDOU] 